\title{
Classroom Observation in Second Language Classrooms: Bridging the gap between theory and practice for pre- service and in-service teachers of
}

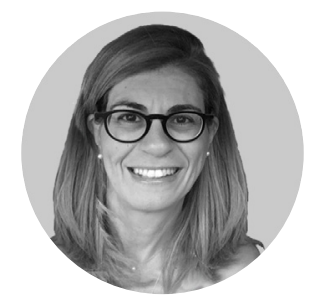

MARIA IAKOVOU

NATIONAL AND KAPODISTRIAN UNIVERSITY OF ATHENS

mariak@phil.uoa.gr

$\mathrm{T}$ his paper is a qualitative study in the framework of a broader project (LETEGR2) that aims to shed light on the way classroom-based observation might contribute to bridging the gap between teaching theory and practice and assisting teacher education. It draws on data derived from pre-service $(n=15)$ and in-service teachers $(n=6)$ who applied the LETEGR2 Classroom Observation protocol in second language classrooms in Greece. Both groups of data are presented according to the observation stages (pre- and post-) in which they have been collected. They are discussed as pre- and in-service teachers' "voices" in terms of the main issues they bring to the fore in relation to L2 learners' profiles, the teaching process and teachers' practices. An attempt is made to link both group of participants' observed behaviors and events to underlying theoretical concepts for second language learning and teaching.

\section{KEYWORDS:}

Classroom observation; LETEGR2; qualitative analysis; preservice/in-service teachers; second language teaching.

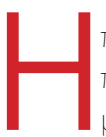

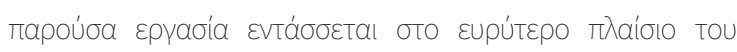

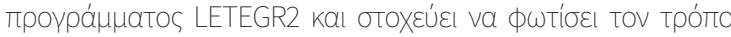

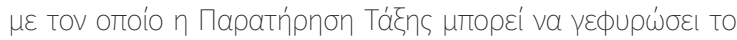

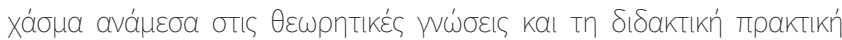

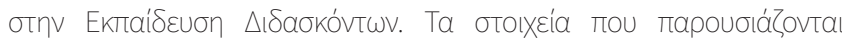

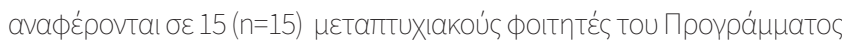

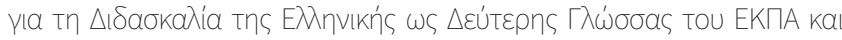

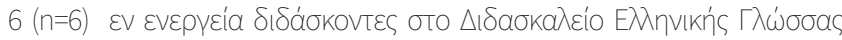

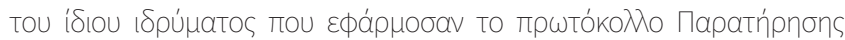

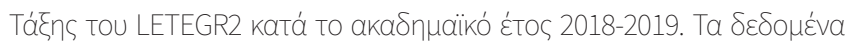

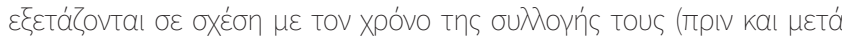

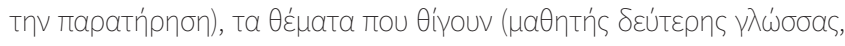
үл

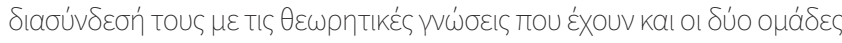

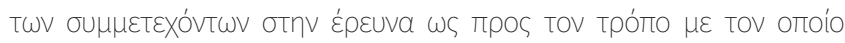

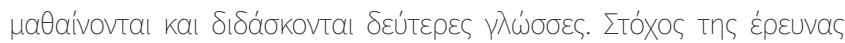

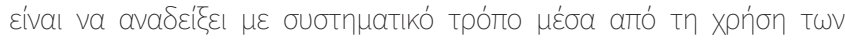

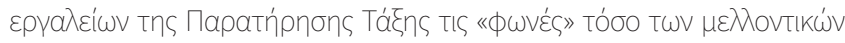

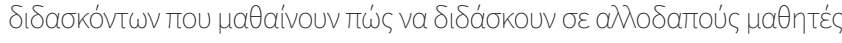

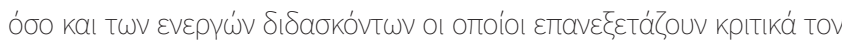

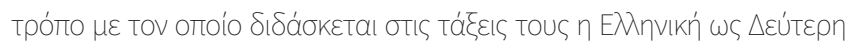

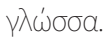

\section{$\Lambda$ EEEIL-KAEISIA:}

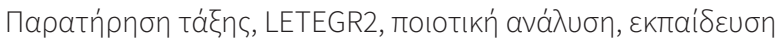

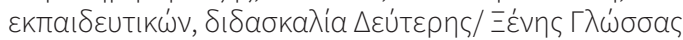




\section{Introduction}

$\mathrm{T}$ eaching languages is a multi-faceted process that cannot be easily broken down into discrete skills to be mastered and be directly transferred from in-service to pre-service teachers who pursue graduate or postgraduate studies in Teacher Education. The latter may be fully competent in learning theories and teaching techniques, but tend to be unaware of what the application of their knowledge in the real-time conditions of a language classroom actually means. Becoming familiar with classroom-based research methods not only enables them to view that setting as a space for self-evaluation, self-reflection and professional development (Ellis, 2012; McKay, 2006; Richards \& Farrell, 2005), but also invites them to match their theoretical background with the classroom reality and to assess research findings and concepts in terms of teaching practices. In other words, undertaking Classroom Observation in the framework of their Practicum offers them the opportunity to "rename" their knowledge with actual data and to reconstruct their stances and beliefs towards the target language and its teaching process (Farrell, 2018) following their exposure to real classroom conditions. However, an integral part of this process is the second language teacher whose role is central in any learning project and, hence, whose professional development is highly dependent on his familiarization with the way his theoretical knowledge about learning theories is reflected in specific teaching practices. This combination becomes even more challenging when it applies to underexplored languages and contexts, such as Greek as a Second/ Foreign language (L2), where a gap in the literature exists as to how the classroom reality may be associated with Second Language Acquisition (SLA) research findings and where the voices of both preand in-service teachers have not been clearly heard during their professional development.

In this context, this paper extends the line of recent research efforts to make these voices heard (Andria, 2020; Andria \& Iakovou, in press) by focusing on pre- and in-service teachers' systematically collected pre- and post-classroom observation data within the framework of the LETEGR2 ${ }^{1}$ project which explores the teaching and learning of Greek as an L2 in different settings. More specifically, this paper draws on two parallel studies of the LETEGR2 project, namely Study 1 titled "Classroom Interaction in different learning contexts" and Study 3 titled "Learning to teach and teaching Greek as an L2: Teacher education, reflection and development". Both take place in classrooms where Greek is taught as an L2 and where in-service teachers teach and pre-service teachers participate as observers of the teaching event. In the following sections, the Classroom Observation protocol is presented, as designed and developed in the framework of the aforementioned project. Moreover, preservice teachers' pre- and post-observation reports as well as in-service teachers' pre-observation questionnaires and post-observation self-reflection forms will be compared and analyzed not only as manifestations of different degrees of familiarization with the teaching process, but also as loci where theoretical knowledge meets the developing teaching expertise. The research questions of the study are summarized as follows:

RQ1:

What kind of themes emerge as key issues of concern for both groups of participants (pre- and in-service teachers) in their observational forms?

RQ2:

What is the difference between pre- and postobservational stages in the way the teaching event is presented and evaluated?

RQ3:

What are both groups of participants' perceptions towards the use of systematic observation as a tool for their professional development while in service or during their period of studies?

\section{Literature review}

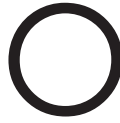
ver the last three decades, classroom observation has emerged as a pivotal tool for measuring, assuring and improving the professional skills and knowledge base of teachers at all stages of their careers, from pre-service to in-service, newly qualified teachers to highly experienced practitioners (O'Leary, 2020). Classroom Observation, viewed as a way of gathering information about teaching (Richards \& Lockhart, 2007) within a broader ethnographic framework, allows both observers and instructors to develop, improve and sustain their teaching excellence. It represents a medium through which the process of reflection can be actively nurtured in and fueled from authentic data to which different groups of practitioners are allowed to have joint access. More specifically, the model adopted by this study refers to a participatory classroom observation, that may be defined as a collaborative, reciprocal model of observation where "the observation is not regarded as an end in itself but as a springboard for sharing ideas and stimulating reflective dialogue' (O'Leary \& Price, 2017, p. 114-115). It aims at providing newly qualified teachers with familiarity with the ideas and practices of their highly experienced co-partners by involving both of them in a fruitful "dialogue" before and after the observational event. This dialogue may offer valuable insights for their professional development, as many studies conducted in different settings so far have attested (Escobar Urmeneta, 2010, 2013; Escobar Urmeneta \& Evnitskaya, 2013; Lieberman, 2009; Wragg, 1999).

\section{The LETEGR2 Classroom Observation protocol}

Whe present classroom observation-based research represents a key element of the LETEGR2 project on which both Studies 1 and 3 are based. More specifically, 
on the one hand, Study 1 aims at analyzing classroom interaction between the language teacher and learners in the contexts of teaching Greek as a Second and as a Foreign Language $^{2}$. On the other hand, Study 3 , which is embedded in the lifelong learning framework, focuses on teachers' perceptions of their own work and approaches pre- and in-service teachers' understandings of the whole teaching/ learning process. Both pre- and in-service teachers are given the opportunity to reflect on the observation in which they have participated and to assess the type of education they have received during their professional development. They are also invited to evaluate their theoretical knowledge when this is activated under classroom conditions. As such, both Studies benefit from the use of the Classroom Observation protocol which they apply consistently, as described below (see also Andria, 2020; Andria \& Iakovou, in press).

\subsection{Context and Participants}

The present study draws on the particular part of the broader LETEGR2 project which was implemented in the context of learning Greek as a Second Language in Greece. More specifically, it deals with the data collected from November 2018 to February 2019 in the framework of the Practicum of the Master's (MA) Programme on Teaching Greek as an L2. In fact, data collection took place at the premises of the Modern Greek Language Teaching Center of the National and Kapodistrian University of Athens. The main part of the LETEGR2 project is tightly connected to this specific MA programme, which for long has been the only one addressed to future teachers of Greek as an L2, as well as to this specific Teaching Center that belongs to the University. By gaining access to the language courses offered by this Teaching Center, the LETEGR2 project approaches studentteachers' and in-service teachers' perceptions and beliefs and provides the opportunity to build bridges between the theoretical background of the first and the teaching expertise of the latter.

Participants in this study fall in the following two groups:

The first group of participants are MA students enrolled in the one-semester compulsory course entitled "Practicum: Teaching methodologies- teaching expertise building through classroom observation" $(n=15)$. This module is taught in the last semester of their MA Programme on Teaching Greek as an L2 and meets the requirements of a classroom-based practice. Postgraduate students who attend this course hold a Bachelor's Degree either in Education or in Linguistics and are accepted in the MA Programme after a selection process that includes a combination of a written exam and an oral interview. The course lasts for two years (four academic semesters). Participants in the current study are 15 postgraduate students of the academic year 20182019. They are all women and their average age is 29.2 years. Before reaching the last semester of their study and attending this specific module of the Practicum, students have been taught other theoretical subjects, such as L2 learning theories and teaching techniques for different language skills. In this study, all postgraduate students are referred to as pre-service teachers.

The second group of participants are in-service teachers who teach Greek as a Second Language at the aforementioned academic institution and allowed the application of the observation protocol in their language courses $(n=6)$. Their teaching experience, as identified by the criterion of their teaching years (Tsui, 2012), ranges from 4 to 25, with a mean value of 15.9 years. They are all women with an average age of 38.7 years and they all hold a MA degree in Language Teaching or SLA. Two of them also hold a PhD in Applied Linguistics. Both groups of participants represent the main teacher profiles that the LETEGR2 project is intended to focus on: potential and actual teachers of Greek as an L2, studying and working in Greece and willing to explore the ways they may improve their teaching techniques and/ or evaluate their professional development through the experience gained in this context.

\subsection{Procedure and Instruments}

For the majority of participants in the LETEGR2 project, this was the first time they were provided the opportunity to observe language classes in situ. All language lessons were video-recorded and all individuals' data were protected and anonymized. Therefore, prior to any data collection, both teachers and L2 learners had to complete personal consent forms providing their written permission for the videorecordings, while at this same stage pre-service teachers had to fill in their individual pre-observation charts. After the completion of all these forms, the observation started. The camera was placed in the back of the classroom, so that it would focus exclusively on the teacher's moves and gestures during the lesson. Once the lesson was over and the observation was completed, pre-service teachers were given the opportunity to ask the instructor additional questions about issues that drew their attention during their observation and, on the other hand, to reflect on some critical points of the teaching procedure. After this semi-structured interview, an open discussion followed between the academic supervisors of the "Practicum" and the participants in the specific observation. The aim of the discussion was, first, to explore the organizational units of each language lesson by analyzing the teaching techniques that had been used for the implementation of each learning goal and, secondly, to reflect on the situation to which observers and observees had been exposed. Data derived from these observation stages were included in the reflection forms, where studentteachers were free to express their point of view in relation to the observation they had participated in.

Taking into account that each observation consisted of two discrete stages (pre- and post-) and addressed two different groups of participants with different degree of expertise, the tools were designed accordingly. In particular, before observations, pre-service teachers completed a preobservation chart with three open-ended questions focusing 
on their expectations regarding the lesson they were about to observe. The in-service teacher of the particular class completed a structured questionnaire which had been developed in the framework of the MA Programme by the pre-service teachers themselves and contained 22 items (8 open-ended and 14 multiple choice questions) that elicited different types of information (personal data as well as personal opinions) concerning issues such as teaching experience, lesson planning, attitudes and stances towards teaching Greek as an L2.

In the post-observation stage, pre- and in-service teachers completed certain forms which were self-reflective in nature and related to the language lesson they had been exposed to. On the one hand, pre-service teachers used the teaching event, in which they had participated as real-time observers as a stimulus. Afterwards, they had the opportunity to process anew the particular teaching event in its video recorded form in order to complete their post-observation chart. This chart, was an observational form that consisted of 6 open-ended questions adapted by the LETEGR 2 research group from Pallarés (2017a, 2017b). All questions related to the main points of the language course they had participated in and elicited information about their feedback on it. On the other hand, each in-service teacher used her own videorecorded lesson as a stimulus which she had the opportunity to watch at any time after its recording. Based on this selfobservation, she had to answer 9 open-ended questions that activated her self-reflection on her own teaching style, the achievement (or not) of the learning goals she had set and issues she might not be aware of during her classroom performance, such as her pronunciation, the speed of her talk, her body gestures or her learners' reactions.

By recording their experiences in two phases, before and after the observation of the teaching event, both participants in the project were invited to express their thoughts and to refer to issues related to the content of the lesson and to classroom management which aroused their interest either positively or negatively. Finally, after collecting all post- observation charts, pre-service teachers participated in a focus group under the guidance of the researcher. Through the focused discussion, which was related to the usefulness of the classroom-observation methodology, they attempted to reach useful conclusions concerning their participation in the LETEGR2 observation protocol and the way it helped them prepare for their further teaching practice. All instrumentsoriginally written in Greek - are translated in English and can be found in the Appendix. Table $\mathbf{1}$ below summarizes the instruments used in this study.

\subsection{Data collection}

Data collection resulted in 90 pre- and 90 post-observation forms completed by pre-service teachers (i.e. 15 postgraduate students) who conducted 6 observations each, 6 teachers' pre-observation questionnaires and 6 post-observation forms completed by teachers who observed themselves in this process. The lessons cover all levels of the Common European Framework of Reference for Languages (CEFR) (Council of Europe, 2001) (A1-C2, according to L2 learners' placement which had taken place prior to their enrolment in this educational institution). Data have been assigned the following codes according to the collection time and the person who conducted the observation: (1a) pre/ post, if data refer to pre-service teachers' observation forms, (1b) $\mathrm{PRE} / \mathrm{POST}$, if data are derived from the in-service teachers' questionnaires or self-reflection forms, respectively, (2) 1-6, according to their numerical order for the six videorecorded lessons (3) with the two or three first letters of the name and the surname of each pre- and in-service teacher who participated in the observation and wrote her own text. Likewise, for coding the transcribed focus group discussion data a number from 1 to 5 was assigned to the pre-service teachers who participated. In this sense, the initials "fg" indicate that the extract is taken from the focus group transcription and the number corresponds to the studentteacher who gave the particular answer.

\section{Pre-observation}

Pre-service teachers

Charts with 3 open -ended questions
Questionnaires with 22 items

\section{Post-observation}

- Charts with 6 open-ended questions based on Pallarés (2017a, 2017b)

- Semi-structured interview with the language teacher

- Focus group on a set of questions related to the classroom- observation methodology

- Semi-structured interview on the language course with the pre-service teachers

- Self-reflection forms with 9 open-ended questions

Table 1. Instruments of the study. 


\section{Data analysis}

$\mathrm{n}$ this paper, an attempt is made to approach the data described in the previous section from a qualitative point of view, the aim being to shed light on the way the particular methodology of participatory classroom observation might contribute to bridging the gap between teaching theory and practice. The data were thematically analyzed under a thematic content analysis model (Cohen et al., 2011) and were assigned tags which focus both on the before and after of each teaching session, as explained below. The tags refer to issues that have been raised, such as expectations, judgements, suggestions, observations or evaluations. They are all related to different parts of a teaching event, such as the learner, teaching materials, techniques or routines to which both pre- and in-service teachers had access through their systematic observation and are associated with different aspects of L2 learning and teaching principles. This assignment of tags to pre- and in-service teachers' scripts assists the analysis, interpretation and comparison of the data to be presented.

\subsection{Pre-Observation stage}

In the pre-observation stage, pre-service teachers recorded their expectations, while in- service teachers provided information about the subject of their observation. Through their descriptions it becomes obvious that at the centre of their accounts lies the L2 learner as the final recipient of each teaching practice.

\subsubsection{Pre-service teachers' pre-observation}

LEARNER is one of the tags found in all pre-observation charts. It is associated to particular teaching techniques, the choices made about the stages of the teaching procedure and the decisions taken about the final teaching product. Consequently, all descriptions provided by pre-service teachers are directly dependent upon the theoretical knowledge that learners' identities - as they emerge from their language level in Greek (Beginners or Advanced), their linguistic background (same or different first language (L1)) and their motivation (the reason why they learn the language)—set the ground for constructing each lesson. A result of this belief is that none of the observers expects a lesson which is the same for everybody (no preobservation chart, even of the same participant, is similar to the following ones), but a lesson which is adapted to different learners' profiles. In this sense, each language lesson activates pre-service teachers' theoretical knowledge about how the teaching process can be individualized and tailored to each learner's needs. All their expectations are formulated as an explicit question about issues that may be of concern in every teaching process (language in which the lesson is conducted, type of linguistic input, the role of L1, development of linguistic fluency rather than accuracy, assessment of language skills). Consequently, all questions filtered by and dependent upon L2 learners' language level in every class bring to the fore the theoretical background of pre-service teachers while expressing their expectations (extracts $\left.(\mathbf{1})-(\mathbf{8})^{3}\right)$. More specifically:

a) L2 learners' level affects the linguistic code that the lesson is conducted in (use of mediate language, language simplification). The lower the level, the higher the concern about the linguistic code that the lesson will take place in (1 and 2). The same concern is caused by learners' homogeneity in terms of their linguistic starting-point (3), specifically about whether or not to use a mediate language:

(1) Taking into account that the lesson is at A1 level, [LEARNER] I'm even more concerned about the teaching technique that will be used, particularly about the language that will be used in the lesson (whether the lesson will be conducted in Greek or whether another mediate language will be systematically used and, particularly, the English language). [OBSERVER'S EXPECTATION_LANGUAGE] pre_2_VI

(2) I wonder how the teacher can provide new input in simple words [OBSERVER'S EXPECTATION LANGUAGE] at the beginner's A level. [LEARNER] pre_2_KK

(3) Even now that I am aware of the fact that students' level is intermediate but that they share the same first language (Chinese), [LEARNER] I am concerned about whether the teacher will use a mediate language or not and if yes, in which cases and whether students will use a mediate language or not in order to facilitate their in-between interaction. [OBSERVER'S EXPECTATION_LANGUAGE] pre_5_AA

b) Likewise, pre-service teachers connect the learners' level to their linguistic background and the reason they are engaged in the process of learning Greek. The class is characterized as "special" when it displays two unexpected features: homogeneity in terms of the $\operatorname{L1}(\mathbf{4}, \mathbf{5})$ and homogeneity in terms of the reason for learning the target-language (6). The result in such cases is a concern about how those two elements could affect the objectives of each level:

(4) When I was informed that we are going to observe this "special" class, characterized by homogeneity in terms of language level and at first language (L1) [LEARNER], (...) I wonder whether the common but at the same time very different L1 will play a beneficial or obstructive role in the learning process. [OBSERVER'S EXPECTATION_LANGUAGE] pre_5_VSI 
(5) I wonder [OBSERVER'S EXPECTATION] how the instructor will be able to take advantage of the characteristics of this homogenous audience [LEARNER] and engage them in activities focused on developing their linguistic fluency in parallel with the acquisition of linguistic accuracy provided by a structure-based lesson.

[OBSERVER'S EXPECTATION_LEARNING

GOALS] pre_5_KK

(6) I wonder [OBSERVER'S EXPECTATION] whether Erasmus students have different needs and "requirements" from the rest of the students at the intermediate level [LEARNER] and whether they pursue a deeper connection with the Greek language and culture [OBSERVER'S EXPECTATION LEARNING GOALS] because of their student status and their educational background [LEARNER]. pre 3 VSI

c) Finally, the language level is connected both with the use of particular learning strategies as well as with the selection of particular teaching models. In the first case (see 7), the observer searches for ways in which the level can be reflected through the activation of specific strategies in oral speech or the vocabulary of learners themselves. In the second one (8), a concern is raised about the degree to which the level can influence the selection of particular teaching models for the teaching of grammar (inductive vs. deductive grammar teaching):

(7) Taking into account that the students' level of the particular class is very high (C1), [LEARNER], I am particularly interested in observing how well students can use the language, particularly in oral speech (e.g. formulation of more complex grammatical structures) or they can proceed in finding the meaning of a word they definitely possess at this level (e.g. recognition of words sharing a common etymology, breaking a word in its constituents without difficulty). [OBSERVER'S EXPECTATION_LEARNING STRATEGIES] pre_4 VI

(8) I wonder [OBSERVER'S EXPECTATION] what an intermediate level [LEARNER] in relation to grammar teaching means, if, in other words, theory would come first and then the relevant exercises (most probably mechanical drills) or vice versa, from practice to theory. [OBSERVER'S EXPECTATION_TEACHING PRACTICE] pre_3_VI

Of particular importance is hence that, as the pre-observation charts completed by student-teachers illustrate, L2 learners' level appears as a key factor in determining their expectations.
Through their expectations, emerges their need to observe the extent to which the theoretical knowledge they have gained about the role of certain learning and teaching principles can be applied in the actual conditions of a language lesson and adjusted accordingly to the characteristics of their learners. They illustrate, in this way, as it is expected, their low degree of familiarity with the teaching practice, which Classroom Observation is called to address.

\subsubsection{In-service teachers' pre-observation}

On the contrary, the pre-observation questionnaires completed by the teachers of each class reflect to a higher degree the stored theoretical knowledge and experience related to their teaching practice. This experience allows them to proceed to generalizations about the role of learner proficiency levels through the way they use certain routines and teaching techniques. Therefore, their answers are significantly similar: (a) in the way they view the degree of difficulty of each proficiency level, which is not explicitly defined $(\mathbf{9}, \mathbf{1 0})$; thus, they do not consider a certain level as displaying a higher degree of difficulty compared to the rest (11):

(9) Each level has its own distinctive difficulties. [JUDGEMENT_GENERALIZATION] In this sense, the differentiation of teaching is not quantitative but qualitative. PRE_1_MA

(10) In my view, every level has its own difficulty, [JUDGEMENT_GENERALIZATION] which depends not only on the level itself but also on students' profile and needs. PRE 2 SK

(11) Every level has its own difficulty [JUDGEMENT_ GENERALIZATION] and I don't think that some is more difficult than the other. PRE_5_EN

In addition, their answers are similar (b) in the way they state that they resort to using a mediate language in their lessons, since they describe it as a very special circumstance (12, 14 and 15) which is not initiated by themselves rather but by their learners (13):

(12) I use a mediate language only when it is absolutely necessary and depending on the class, that is: on the level (almost never at higher levels), on students' needs (I may use a mediate language on the first day to justify why I don't use a mediate language in general), but in the lesson I respond only when my students provide a word in a foreign language. [JUDGEMENT GENERALIZATION_LANGUAGE] PRE _5_EN 
(13) I myself almost never use a mediate language. If needed I try to elicit from the audience the English language. Usually when there is something unclear, I give examples until someone provides the word in a mediate language (English or Russian). [JUDGEMENT GENERALIZATION_LANGUAGE] PRE _4_ED

(14) With advanced students no, very seldom (only to make a connection with respective words-expressions) [JUDGEMENT GENERALIZATION LANGUAGE] PRE 2 SK

(15) I try to use mediate language as less as possible when I teach because a) not all students are familiar with it, b) they benefit from the use of Greek as an acquisition tool. [JUDGEMENT GENERALIZATION_LANGUAGE] PRE _1_MA

Finally, their answers seem to be significantly similar (c) in the way they handle the heterogeneity of their audience by functioning as a balancing force (18), through the cooperation (17) of the most proficient with the weaker students (16):

(16) Assigning more and harder tasks and activities to the most proficient ones. Supportive material focused to the specific needs of the weaker ones. [JUDGEMENT G E N E R A L I Z A T I O N C L A S S R O O M MANAGEMENT] PRE _1_MA

(17) I try to encourage cooperation. I try to adapt my material to the needs of everyone / as many learners as possible. [JUDGEMENT_ GENERALIZATION CLASSROOM MANAGEMENT] PRE_3_MG

(18) I try to give a balanced lesson in terms of its level of difficulty. [JUDGEMENT_ GENERALIZATION LEARNING GOALS] PRE 4 4 SD

Consequently, the difference between the two groups, preservice and in-service teachers, is that the former start from theory and try to find a way to implement it in the classroom by asking crucial questions about how this might be achieved. The latter, on the other hand, because of their strong familiarity with teaching practice, generalize their personal accounts and do not seem, at least at the beginning of the observation process, to wonder about the adequacy of their own views with regard to SLA principles. In other words, as far as pre-service teachers are concerned, the preobservation stage invokes their former theoretical knowledge and creates a "hook" which connects it to the particular teaching event. On the contrary, in-service teachers only draw on their teaching expertise and seem to be "disconnected" from more theoretical knowledge. This different perspective is also reflected in the discourse that both groups employ in their scripts as far as their degree of certainty is concerned. The group of pre-service teachers is in constant search for answers to the questions they ask themselves (which, as was noted, can be completely different per student and occasion), while the group of in-service teachers seem more confident when providing the final product of their teaching experience by making reference to techniques and routines they already use (with a high degree of uniformity in the type of judgements they express and the tools they mention).

\subsection{Post - Observation stage}

In the post-observation stage, the trajectory followed by both groups of participants seems to be the opposite: their descriptions begin from the observed events and the participants themselves search for ways to connect them with their initial theoretical constructs. In this context, issues that arise in the pre-observation stage recur in the postobservation process in the form of answers through specific examples, teaching descriptions and processes.

\subsubsection{Pre-service teachers' post- observation}

The first topic, which is identified in all pre-service teachers' post-observation charts as a key element of their initial concern, is the language in which the lesson can be conducted. The language of the lesson is connected to L2 learners' level (20) and the linguistic item taught (21). In addition, it is also related to the presence and position of learners' first languages in the class (19) and generally, the type of linguistic management chosen by the teacher in relation to the target language, that is, Greek (22). Finally, an important part of the same topic (Language) is covered by meta-linguistic references (23), (24), (25) about serving particular teaching purposes (e.g. in a grammar lesson).

Their descriptions illustrate that classroom observation can provide an answer to their concerns and, hence, that studentteachers can positively evaluate and mention all events which provide answers to their initial questions:

a) If the teacher needs to know learners' mother tongues:

(19) Through the particular observation, it became evident that the complete lack of knowledge of students' mother tongue (on the teacher's part) may not be an obstacle after all [OBSERVATION LANGUAGE] (since this was something that caused stress to me from the beginning) [NEGATIVE EVALUATION] post_1_VI 
b) If the target-language can be used already from the beginning of the learning process:

(20) Through the particular observation, I was positively surprised [POSITIVE EVALUATION] by the fact that, at an initial stage, the lesson can be smoothly conducted by using the $\mathbf{L} 2$ (target-language) [OBSERVATION LANGUAGE]. post_2_VasI

(21) What seemed difficult to me [NEGATIVE EVALUATION], in the particular lesson was the way the meaning of unknown words and expressions were explained particularly at this level where students' lexical repertoire and their available strategies are still limited and, respectively, where there are grammatical phenomena such as the agreement between gender, case and number. The teacher brilliantly explained all the unknown vocabulary using various ways (gestures, imitation, definitions, synonyms), she recorded it on the board and without using any metalanguage or any other language she directed her students to the grammatically correct answers. [OBSERVATION_LANGUAGE]. post_3 PA

c) To what extent the learners' mother tongues may appear within the context of the lesson:

(22) The teacher did not discourage the use of L1 among students (in the particular lesson half of the students were French-speaking and they helped each other providing the translation of some unknown L1 words). At the same time, the teacher herself used exclusively the L2. [OBSERVATION LANGUAGE]. I found exceptionally positive [POSITIVE EVALUATION] the fact that, even though the teacher uses only Greek as the language of instruction, she treats with respect her students' choice to make use of familiar codes to help themselves in their learning. [OBSERVATION_ LANGUAGE]. post 4 KK

d) In what way the metalanguage may be provided to learners

(23) I realised that [EVALUATION] the issue of metalinguistic terminology [OBSERVATION_METALANGUAGE] is vital (e.g. the word 'conjugation', which is often found in textbooks of our education system, was never mentioned, but instead the word "group" was used). post_2_TM

(24) I particularly liked [POSITIVE EVALUATION] the indirect way in which the rule of augmentation was expressed (three syllables: so, I don't need the " $\varepsilon "$ "). [OBSERVATION_METALANGUAGE] post_5_VI
(25) I was pleasantly surprised [POSITIVE EVALUATION] by the fact that students were able to cope without knowing the metalanguage. What replaces it is the presentation of grammar/ words/ expressions in formula style. [OBSERVATION_METALANGUAGE] post_6_TM

Of even greater interest are the post-observation charts which use the observed event as a basis for referring to its theoretical "grounding" and for interpreting it through the lens of the acquired theoretical knowledge. This connection allows the observed event to lead to generalizations and invites theory to be used as a basis both for the description of a teaching sequence which has taken place and for the expression of a suggestion about a teaching sequence which has not taken place.

The first case can be identified in the description of a lesson provided by one of the student-teachers, who connects the content of a language lesson with the 4 strands of Nation's (2007) L2 teaching model, i.e. meaning-focused input, language focused learning, meaning-focused output and fluency development. In this way, each part finds its position connecting it with the rest, while its learning objectives are interpreted by this particular theoretical model. In more detail, the incidental teaching of vocabulary "through an explicit definition of the meaning of unknown or difficult words" (26, post_4_VI) belongs to the form-focused language strand. On the other hand, the video-recorded lesson about traditional Mediterranean nutrition, which is processed by students in terms of its oral and written input through comprehension questions, belongs to the meaning-focused first strand. Finally, learners' guided oral production falls under the third strand which results in meaning-focused output, while the free final discussion about their countries' nutritional habits, where each learner provides his own experiential viewpoint, takes on the characteristics of the fourth strand which leads to fluency development. On the basis of this description, the observer ends with the following generalization:

(26) Consequently, even in a 1-1,5 hour- lesson all 4 language skills can be equally effectively 'honed'. [EVALUATION_THEORY] post_4_VI.

On the contrary, when this variety in the implementation of a lesson is missing, the observer goes back to the theoretical tool to support the judgement (27) and/or her improvement suggestion (28) :

(27) Something was missing from the lesson for me. [OBSERVATION]. I would like to see a more complete combination of the four skills (they mainly kept to speaking and in part to listening through the teachers' and learners' input) and there was no production on the stu- 
dents' part, as I expected. Nation's four strands are undervalued!!! [SUGGESTION_THEORY] post_3_MT

(28) It is suggested, then, that beyond presenting new knowledge and the accompanying drills there should be an engagement with new knowledge through speech production activities in order to create meaning-focused output which is the needed outcome in language teaching. [SUGGESTION_THEORY] post_3_GK

In all the above references, the association between observation as a lived experience and the pre-service teachers' initial theoretical background is reflected in their evaluations. Systematic observation prompts observers to connect theory with practice and to act as mediators between these two elements that both feed each other in a successful way. It is indicative of the fact that, the positive atmosphere in the observing groups is not just described, but is linked to Krashen's (1982) affective filter as a defining element of language learning (29), (30). The positive image of a class is either directly or indirectly filtered through this assumption, as can be seen in the following extracts:

(29) The first thing, which has to do with the affective filter, is the pleasant spirit in the classroom both among the students as well as between the students and the teacher. This is credited to the students but to the teacher as well. [OBSERVATION_THEORY] post_2 KK

(30) I was pleasantly surprised by the chemistry between students, despite their differences in terms of age or origin. The positive spirit of the class definitely contributed to maintaining a constructive predisposition towards mastering the Greek language (reduction of Krashen's affective filter / more effective learning) [OBSERVATION_THEORY] post_4_VI

Through all these extracts it becomes obvious that preservice teachers show their readiness to analyse the reality of the classroom through the lens of their prior theoretical knowledge and to make a statement of it through their observations. Consequently, even in an indirect way, they understand that the particular classroom-based methodology fills the existing gap between the ready knowledge of bibliography and the ways it can be implemented in a classroom of teaching Greek as an L2. This gap is even more directly and explicitly identified in the answers provided by pre-service teachers in the focus group when asked about the extent to which the knowledge they had before the Classroom Observation was modified through it. This change is stated in an explicit and absolute way (31) to the same degree that the transition from theory to practice is stated (32), through their exposure to data coming from "living examples, living learners" (33):

(31) I learned things I hadn't realized even for the Greek language [THEORY TRANSFORMATION] fg_1

(32) My expectation was to put certain theoretical issues in order and I think that this was achieved, meaning that before the Practicum I could not imagine how all this theoretical background we had gained in the first year of our studies could be put into practice. I think that this need was covered. [THEORY TRANSFORMATION] fg_2

(33) I will also agree with the theory which we saw in practice and that we saw in reality a class of Greek and it's very different from what we have in our minds $[\ldots]$ it was really nice to see live examples, live students who learn Greek. [THEORY TRANSFORMATION] fg_3

Finally, in order to explain the significant impact of the systematic observation on understanding how teaching events are connected to previous theoretical knowledge and hence, how theory and practice feed each other in L2 teaching, the same students end up, on the one hand, considering the particular module as the "core" of their MA programme (34), (35) and, on the other hand, projecting this observation as a technique which might allow them to manage the conditions of their own classes and the learning abilities of their own learners (36) in the future:

(34) I will just say that it gave us the opportunity to connect the theoretical background with the practical part and this is what I consider important in the framework of an MA programme. Basically, it is the most important in an MA programme. [OBSERVATION_MA CORE ] fg_4

(35) It is the most representative one, from all the rest of the MA programme, right? I mean, if we are to teach, this is the least we could do. [OBSERVATION_MA CORE] fg_1

(36) for future use, if I, for example, want to assess something which does not work well in my lesson, I could say: "why can't she acquire this, why can't she acquire that" perhaps through self-observation by taking notes and so on I could put things down and be more objective about the way I myself work as a teacher. [OBSERVATION_FUTURE USE] fg_3 


\subsubsection{In- service teachers' post-observation}

A similar type of transition from the observed events to their theoretical starting-points is identified in teachers' self-reflection forms. In addition, observation is used as an impetus for identifying elements and information which are often lost during the teaching process. Through these forms, teachers can refer to their own teaching practices trying to interpret their objectives, to discover their strong and weak points and to self-assess. Common points in their selfreflective process emerge through the way in which

(a) they trace from the observed event back to its generalized theoretical constructs (37) - (40)

(b) the observation functions in their self-evaluation (41) (48)

(c) they position themselves towards the particular methodology (49) - (51).

As far as the first point is concerned, the connection between practice and theory is initiated by teachers in their effort to interpret the points which functioned effectively (37), (38) as well as those which turned out to be problematic in the course of their lesson (39), (40). In this sense, the effectiveness or ineffectiveness of their teaching practices seems to be inextricably connected to the presence or absence, respectively, of particular stages in the teaching process. These stages are dictated by teachers' theoretical knowledge about the way their lesson should have been structured. In their positive accounts, the used teaching materials are initially described and next traced back to the supporting theory. The underlying aim of this description is to interpret the choices made both at the level of vocabulary (37) as well as at the level of grammar (38):

(37) First of all, the warm-up with the questions about what the students had done during the previous weekend [OBSERVATION_TEACHING STAGES] helped them, in my opinion, to retrieve relevant vocabulary and Simple Past types they had been taught, while at the same time it aroused their interest, since they were asked to talk about familiar experiences. [OBSERVATION_TEACHING MATERIAL]. In this way, I think a smooth transition to the new teaching object was ensured, both at a cognitive background as well as at an emotional engagement level. [OBSERVATION_THEORY] POST_MA

(38) Everything is part of the typical practices I follow in lesson with my (so-called) "scholars' classes" [...] in such classes I place more emphasis on accuracy compared to the one I place on an ordinary A1 class, where I would normally not extensively deal with agreement. This is why I projected photographs of different people in class and we all talked about what the person is wearing in each photo using the definite or indefinite article, adjective and noun. [OBSERVATION_TEACHING MATERIAL].

I wrote all words on the board during the activity and student who wished kept notes. My aim was again to consolidate vocabulary and agreement. I constantly repeated what students were saying in order to identify their linguistic gap, the difference between their linguistic output and the linguistic input I had exposed them to. [OBSERVATION_THEORY] POST_EN

Likewise, in their negative accounts, their reaching back to their theoretical starting-points helps them to make sense of the negative points of the particular teaching practice and to interpret learners' difficulties during the implementation of the teacher's plan in listening (39) or reading tasks (40):

(39) Before watching the video, I didn't try at all to raise expectations about what we were about to watch, we did not express any assumptions about what we were going to come across in the extract. [OBSERVATION TEACHING STAGES] There was no pre-listening stage and it was difficult for students to make connections with the knowledge which was about to follow both in terms of both content and form [OBSERVATION THEORY] POST_MG

(40) The text was demanding without any prior lexical smoothing. So, the pre-reading oral activity of skimming, which invited learners to focus on the main ideas of the text, went to waste. Students did not understand anything and asked me to explain word for word everything they didn't understand. [OBSERVATION TEACHING STAGES]. Responses to their questions could take a different form, if the input to which the learners were exposed was comprehensible. [OBSERVATION_THEORY] POST_JM

What is common in all cases is teachers' readiness to use observation as a tool to reach back to their theoretical knowledge and to rely on it in order to interpret the success or failure of their decisions. At this point, it becomes evident that they function in a way similar to the one found in preservice teachers' post-observation stage.

There is, however, a significant difference in the way inservice teachers use self-observation which is depicted in the second common point of all their self-reflective reports. In this sense, observation becomes not only an interpretive 
but also an evaluative tool in that it enables them to identify points which, as they mention, under other circumstances would have remained unobserved. Their surprise becomes even greater when they realise that these issues become for the first time so intensely manifest and cause their concern about their impact both on their learners and their self-image. These issues are related to:

a) Features of their teacher talk (disproportionate speech time, teacher-centred lesson, use of linguistic features which cannot be noticed by learners or lead to completely different results in terms of their interest arousal and attention):

(41) I realized that I talked a lot (high teacher talking time). [OBSERVATION] The initial questions could be answered through active student participation. Feedback could be provided in a different, more interactive manner. [SELF-EVALUATION] POST EN

(42) I hadn't realized that I repeat my phrases (maybe this facilitates understanding but it's not the kind of teacher talk I thought I produced) [OBSERVATION] and it might be that my students find me extremely boring and ineffective after all!! [SELF-EVALUATION] POST_MG

(43) I was so much surprised [SELF-EVALUATION] by how much I talked and that I repeated the same explanations plenty of times [OBSERVATION]. There were not enough pauses [OBSERVATION] for the "fear of silence". [SELF-EVALUATION] POST JM

(44) Perhaps I should [SELF-EVALUATION] talk less and sometimes let them try harder before I intervene to facilitate them [OBSERVATION]. POST_SD

(45) I had never thought before [SELF-EVALUATION] that using first person plural instead of second in my questions to students relating to whether they had understood something (e.g. "have we understood it?" instead of "have you understood it?"), had better been avoided, [OBSERVATION] because at this level, it might cause confusion. POST_MA

b) Features of their body posture and gestures which they consider unsatisfactory and not supportive as far as their learners' understanding or acceptance are concerned:
(46) I feel my body posture was not effective [SELFEVALUATION] when I crossed my arms in front of my body (as in church) [OBSERVATION] POST JM

(47) My gestures were in many cases exaggerated [OBSERVATION] and would be useful only if my students were beginners and needed support to understand. Now, what I achieved through my gestures, I 'm having difficulty to understand. [SELF-EVALUATION] POST EN

(48) I stand in front of my students [OBSERVATION] very sweet but nerveless [SELF-EVALUATION] and the calmness of my voice [OBSERVATION] puts them to sleep rather than activating them. [SELF-EVALUATION] POST_MG

Finally, in their post-observation forms, teachers underscore in every possible manner that watching and observing themselves is not enough for them in order to become aware of their strong or weak points, to have a rounded view of their class and to become concerned about what could have been done differently. To the contrary, they feel the need to share this observation with other colleagues in an effort to benefit as much as possible from their knowledge and experience, a fact which increases the value of their statements:

(49) It would be of course even more interesting [EVALUATION] if there would be the chance to get feedback from the rest of the observers too (maybe anonymously, so that everyone can freely express his opinion). [OBSERVATION SHARING] POST_MA

(50) Certainly, it would be very good if it could be applied on a regular basis, like peer observation; mutual observation of classes taking place between colleagues. [OBSERVATION SHARING] I think it would be very useful and constructive for everyone, more or less experienced. [EVALUATION] POST_JM

(51) I consider its combination with commentary coming from other individuals [OBSERVATION SHARING] very important [EVALUATION], since this is the only way for me to be able to examine certain parameters that I may ignore [SELF-EVALUATION]. I mean that self-reflection is based on knowledge I have up to now, leaving many aspects of teaching outside critique, because they concern questions which I haven't even posed. [SELF-EVALUATION] At this point, other people's critique is necessary [OBSERVATION SHARING]. POST_EN 
Their statements seem quite similar to those by pre-service teachers, as both of them recognize the transformative role of observation in their professional development as a lifelong technique that may be shared and applied in different teaching settings. As such, they do not consider it as a threat or as an externally imposed assessment. On the contrary, adopting an evidence-based approach in their own work would make their voices systematically heard and processed for the benefit of their learners and themselves.

\section{Discussion}

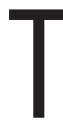
his study joins the recent body of qualitative research which approaches pre- and in-service teachers' voices on teaching and learning to teach Greek as an L2 within the framework of the LETEGR2 project (Andria, 2020; Andria \& Iakovou, in press). Though preliminary, it provides a sufficient number of authentic data that illuminate the relationship of pre-and in-service teachers with the Classroom Observation protocol which is applied for the first time in the context of Greek as an L2. Moreover, in line with other similar recent research conducted in other parts of Europe (see Escobar Urmeneta, 2010, 2013), the findings of the present study provide support for and suggest the importance of classroom observation for teacher education, as well as the significance of self-reflection for teacher professional development and growth. Both groups of participants in the classroom-based research of the LETEGR2 project seem to recognize the benefits of connecting pre-constructed theories and their on-going teaching applications in the interpretation of different teaching events, although they have different starting points and they share different degree of expertise: pre-service teachers draw on theory and try to find ways to apply it in the object of their observation; in-service teachers, though disconnected in the beginning from their theoretical ground, recall it afterwards in their self-reflection and employ it as a tool for the interpretation of their good or inefficient teaching practices. In this framework, both theory and teaching practice resemble two nodes that should be constantly activated in-action and on-action (Schön, 1983) for all language teachers in order to take the lead of their own development. As Escobar Urmeneta (2013, p. 350) puts it, it is an issue of teachers' maturity and emancipation the way they both deal with observational data and L2 literature. The present study, however, indicates that this relationship needs to be reinforced and integrated in all teachers' education curricula. Pre-service teachers consider their Practicum, based on the LETEGR2 Classroom-Observation protocol, as the core of the whole MA Programme on Teaching Greek as an L2, meaning that they realize the significance of this kind of training before undertaking the teachers' role in a real classroom. Similarly, in-service teachers reconsider their own teaching expertise by being given the opportunity to immerse into their own teaching and reflect on it (Andria, 2020; Andria \& Iakovou, in press). Consequently, this study suggests that both groups of participants may benefit from a teacher-led classroom observation.

\section{To conclude}

W e are just at the beginning of the implementation of a new professional ethos for more aware, selfconfident and experienced teachers, who would connect, as Hall (2018) puts it, theory and practice "in ways which are supportive, motivating and sustainable in their daily working lives" (p. 40). LETERGR2 seems to work hard in the right direction for this cause.

\section{Acknowledgements}

This research has been financially supported by the General Secretariat for Research and Technology (GSRT) and the Hellenic Foundation for Research and Innovation (HFRI) (Code: 1656). It also owes gratitude to the Modern Greek Language Teaching Center of the National and Kapodistrian University of Athens for kindly providing the staff, facilities and support to conduct this study. The author would like to owe her gratitude to the anonymous reviewers of this paper for their valuable comments and suggestions, which helped her to improve it. However, all mistakes remain hers. 


\section{Notes}

1 Initials for "LEarning, TEaching and Learning to Teach in GReek as Second/ Foreign (L2): Evidence from different learning contexts".

2 The LETEGR2 project adopts the georgraphical distiction between the terms "second" and "foreign" language, according to Ellis (1994).

3 Original data were written in Greek and here are translated by the author of the paper.

\section{References}

Andria, M. (2020). Learning to teach and teaching Greek as a Second/Foreign Language: A preliminary approach on teachers' and student-teachers' perceptions. In Mackay, J., Birello, M., \& Xerri, D. (Eds.) ELT Research in Action: Bringing together two communities of practice (pp. 49-52). IATEFL.

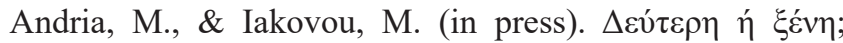

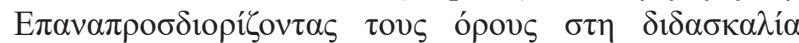

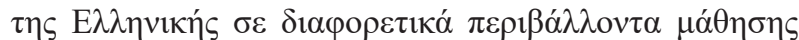
- [Second or Foreign? Redefining the terms in the acquisition of Greek in different learning contexts]. Proceedings of the 14th International Conference on Greek Linguistics (ICGL14), University of Patras, Patras, Greece.

Cohen, L., Manion, L., \& Morrison, K. (2011, $7^{\text {th }}$ edition). Research methods in education. Routledge.

Council of Europe (2001). Common European framework of reference for languages: Learning, teaching, assessment. Cambridge University Press.

Ellis, R. (1994). The study of second language acquisition. Oxford University Press.

Ellis, R. (2012). Language teaching research and language pedagogy. Wiley-Blackwell.

Escobar Urmeneta, C. (2010). Pre-service CLIL TeacherEducation in Catalonia: Expert and novice practitioners teaching and reflecting together. In Lasagabaster, D. \& Ruiz de Zarobe, Y. (Eds.) CLIL in Spain: Implementation, results and teacher training (pp.189-218). Cambridge Scholars Publishing.

https://doi.org/10.1017/s0272263112000289

Escobar Urmeneta, C. (2013). Learning to become a
CLIL teacher: Teaching, reflection and professional development. International Journal of Bilingual Education and Bilingualism, 16(3), 334-353.

https://doi.org/10.1080/13670050.2013.777389

Escobar Urmeneta, C. \& Evnitskaya, N. (2013). Affording students opportunities for the integrated learning of content and language. A contrastive study on classroom interactional strategies Deployed by two CLIL teachers. In Arnau, J. (Ed.) Reviving Catalan at school: Challenges and instructional approaches (pp. 158-182). Multilingual Matters LTD/ Institut d' Estudis Catalans.

https://doi.org/10.21832/9781783090266-010

Farrell, T. (2018, $2^{\text {nd }}$ edition). Reflective language teaching. Practical applications for TESOL teachers. Bloomsbury.

Hall, G. (2018). Theory, theories and practices in ELT: 'Believing and doubting'. In J. Mackay, M. Birello \& D. Xerri (Eds.) ELT Research in action: Bridging the gap between research and classroom practice (pp. 37-40). IATEFL.

Krashen, S.D. (1982). Principles and practice in second language acquisition. Pergamon.

Lieberman, J. (2009). Reinventing teacher professional norms and identities: The role of lesson study and learning communities. Professional Development in Education, 35(1), 83-99.

https://doi.org/10.1080/13674580802264688

McKay, S. (2006). Researching second language classrooms. Lawrence Erlbaum Associates.

Nation, I.S.P (2007). The four strands. Innovation in language learning and teaching, 1(1), 1-12.

https://doi.org/10.2167/illt039.0

O'Leary, M. (2020, $2^{\text {nd }}$ edition). Classroom observation: A guide to the effective observation of teaching and learning. Routledge.

O’Leary, M. \& Price, D. (2017). Peer Observation as a springboard for teacher learning. In O’Leary, M. (Ed.) Reclaiming Lesson Observation: supporting excellence in teacher learning (pp. 114-123). Routledge.

https://doi.org/10.4324/9781315621838-21

Pallarés, O. (2017a). Classroom Practice form. Unpublished internal use tool. LED Research Group.

Pallarés, O. (2017b). Participant Observation in CLIL Classrooms. Unpublished internal use tool. LED Research Group. 
Richards, J. \& Farrell, T. (2005). Professional development for language teachers: strategies for teacher learning. Cambridge University Press.

Richards, J. \& Lockhart, C. (1994). Reflective teaching in second language classrooms. Cambridge University Press.

Schön, D. (1983). The reflective practitioner: how professionals think in action. Basic Books.

Tsui, A. (2012). Understanding expertise in teaching. Cambridge University Press.

Wragg, E. (1999). An introduction to classroom observation. Routledge. 


\section{Appendix A}

In-service teacher's pre-observation questionnaire

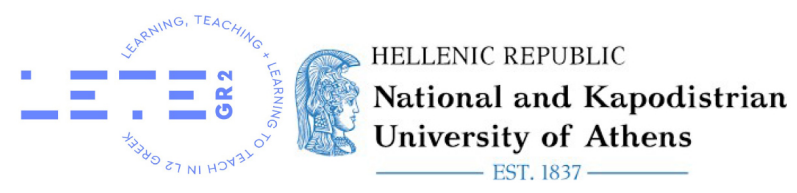

\section{INSTRUCTOR'S QUESTIONNAIRE}

Name:

Studies:

1. Which other languages, apart from Greek, do you speak and at what level?

2. How many years have you been teaching Greek as an L2?

3. Where have you taught Greek as an L2?

4. Which levels have you dealt with and to what extent? ( 1 = Not at all, 2 = A little bit, 3 = Somewhat, 4 = Quite a bit, 5 = Very much)

$\begin{array}{lllllll}\text { a. } & \text { A1 } & 1 & 2 & 3 & 4 & 5 \\ \text { b. } & \text { A2 } & 1 & 2 & 3 & 4 & 5 \\ \text { c. } & \text { B 1 } & 1 & 2 & 3 & 4 & 5 \\ \text { d. } & \text { B2 } & 1 & 2 & 3 & 4 & 5 \\ \text { e. } & \text { C1 } & 1 & 2 & 3 & 4 & 5 \\ \text { f. } & \text { C2 } & 1 & 2 & 3 & 4 & 5\end{array}$

5. Which level do you think poses the most difficulty to a teacher? Justify.
a. A
b. B
c. C

\section{LESSON PLANNING}

( $1=$ Not at all, 2 = A little bit, $3=$ Somewhat, $4=$ Quite a bit, $5=$ Very much)

6. For developing your material, you take into account:

a. The curricula and the level of language proficiency

b. The textbook

c. Learners' motivation and needs

d. Other

7. Your teaching aims at:

a. Focusing on grammatical phenomena.

b. Developinglearners' communicative competence.

c. Combining the above two.

d. It differs depending on the audience

$\begin{array}{lllll}1 & 2 & 3 & 4 & 5 \\ 1 & 2 & 3 & 4 & 5 \\ 1 & 2 & 3 & 4 & 5 \\ 1 & 2 & 3 & 4 & 5\end{array}$

LEARNING, TEACHING AND LEARNING TO TEACH IN GREEK AS A SECOND/FOREIGN LANGUAGE: EVIDENCE FROM DIFFERENT LEARNING CONTEXTS (LETEGR2, RESEARCH CODE1656) 


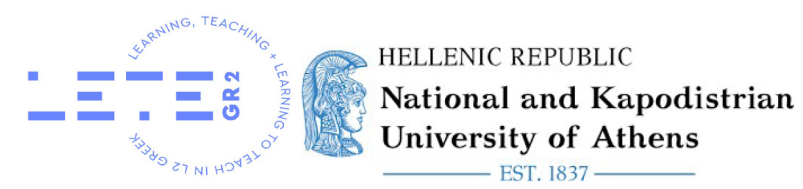

8. While teaching Greek as an L2:
a. You first teach the linguistic items and then you deal with texts related to the material (Analytic method)
$\begin{array}{lllll}1 & 2 & 3 & 4 & 5\end{array}$
b. You provide the texts from which you deduce the linguistic items to be taught (Synthetic method).
$1 \quad 2 \quad 3 \quad 4 \quad 5$
c. You combine the previous two.
$\begin{array}{lllll}1 & 2 & 3 & 4 & 5\end{array}$

9. Learners have greatest difficulty in:
a. Grammar learning
b. Vocabulary learning
c. Pronunciation
d. Dictation

10. Do you use mediate language in the classroom? Justify.
a. Yes
b. No

\section{ACTIVITIES}

11. How do you react when one of your learners makes a mistake in his oral speech?
a. You interrupt him/her and you correct him/her on the spot.
b. You let him/her complete his answer and you correct him/her afterwards.
c. You do not correct the mistake.
d. Other: it depends on the type of the mistake, the aim of the activity and the learner's personality.

12. How do you correct the exercises that students complete at home?
a. By yourself, noting the mistakes.
b. All together in the classroom.
c. One learner corrects the other.
d. Other: through all the above ways.

13. ( $1=$ Not at all, $2=$ A little bit, $3=$ Somewhat, $4=$ Quite a bit, $5=$ Very much) ( $1=$ Not at all, 2 = A little bit, 3 = Somewhat, 4 = Quite a bit, 5 = Very much)
a. individually
$\begin{array}{lllll}1 & 2 & 3 & 4 & 5\end{array}$
b. In pairs
c. In groups
$\begin{array}{lllll}1 & 2 & 3 & 4 & 5\end{array}$

LEARNING, TEACHING AND LEARNING TO TEACH IN GREEK AS A SECOND/FOREIGN LANGUAGE: EVIDENCE FROM DIFFERENT LEARNING CONTEXTS (LETEGR2, RESEARCH CODE1656) 


\section{HELLENIC REPUBLIC

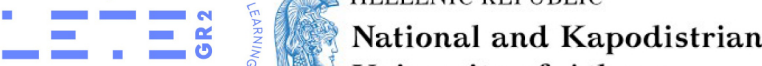 \\ University of Athens}

14. For group activities, the groups are formed:

a. By learners themselves

b. By the teacher (proportion of competent and less competent learners in a group)

c. Randomly (e.g. depending on the way they are seated)

\section{LEARNING MATERIAL / TEXTBOOK}

15. What do you use in your teaching and to what extent?

( $1=$ Not at all, 2 = A little bit, 3 = Somewhat, 4 = Quite a bit, 5 = Very much)

a. The textbook

b. Personally developed material

c. Digital tools

d. Other sources

$\begin{array}{lllll}1 & 2 & 3 & 4 & 5 \\ 1 & 2 & 3 & 4 & 5 \\ 1 & 2 & 3 & 4 & 5 \\ 1 & 2 & 3 & 4 & 5\end{array}$

\section{Which textbook do you prefer in your teaching? Explain.}

\section{SOCIOCULTURAL BACKGROUND}

17. Mention two main ways in which you deal with the problems of heterogeneity in your classroom:

18. Which practices do you follow in order to familiarize your learners with the Greek culture and the Greek norms?
a. You present authentic material from the arts industry (e.g. TV show excerpts).
b. You organize thematic days (e.g. Mediterranean cuisine day).
c. You share personal experiences.
d. Other

\section{TECHNIQUES/ATTITUDES}

19. The ways of vocabulary learning which you prefer for your learners are: ( $1=$ Not at all, 2 = A little bit, 3 = Somewhat, 4 = Quite a bit, 5 = Very much)
a. New vocabulary and translation in Ll or in a mediate language
b. New vocabulary and synonyms, definition in Greek $\quad \begin{array}{lllll}1 & 2 & 3 & 4 & 5\end{array}$
c. Combination
d. Other

$\begin{array}{llll}2 & 3 & 4 & 5 \\ 2 & 3 & 4 & 5\end{array}$

LEARNING, TEACHING AND LEARNING TO TEACH IN GREEK AS A SECOND/FOREIGN LANGUAGE: EVIDENCE FROM DIFFERENT LEARNING CONTEXTS (LETECR2, RESEARCH CODE1656) 


\section{- - \\ National and Kapodistrian \\ University of Athens \\ EST. 1837}

\section{FOR TODAY'SLESSON:}

20. Order of lesson in the current course $\left(1^{\text {st }}, 2^{\text {nd }}\right.$, etc. $)$ :

21. Lesson aims (What I will teach):

22. Level of language proficiency:

LEARNING, TEACHING AND LEARNING TO TEACH IN GREEK AS A SECOND/FOREIGN LANGUAGE: EVIDENCE FROM DIFFERENT LEARNING CONTEXTS 


\section{Appendix B}

Pre-service teacher's pre-observation questions

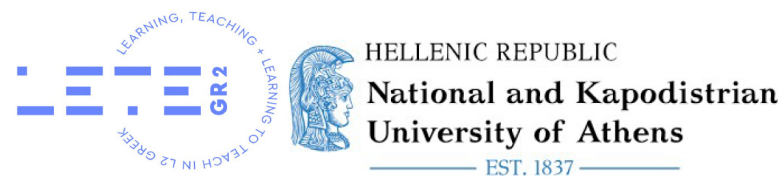

PRE-SERVICE TEACHER Questionnaire

Name:

Date:

Please, answer the following questions in short:

1. What questions do you want to pose to the instructor of this class?

2. Which points of the lesson do you want to focus your attention on?

3. What do you expect from this particular lesson? 


\section{Appendix C}

In-service teacher's post-observation self-reflection form

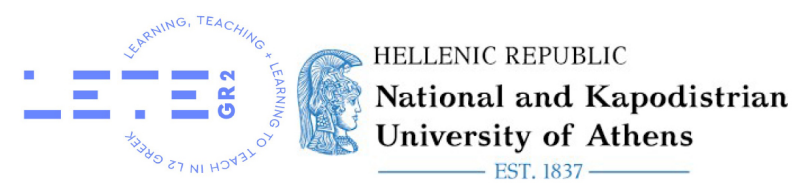

\section{INSTRUCTOR'S NAME:}

DATE:

\section{INSTRUCTOR'S SELF-REFLECTION REPORT}

INSTITUTION: MODERN GREEK LANGUAGE TEACHING CENTER, University of Athens, Greece PROFICIENCY LEVEL:

UNIT:

NUMBER OF SESSIONS:

NUMBER OF STUDENTS:

1. Which were your aims? Was there anything new you intended to try out in this particular lesson (e.g., a new method in the class, the use of different materials, etc.). Why?

2. What went well? Why? Mention (3) aspects which you think worked well in your lesson.

3. After watching your video-recorded lesson, is there anything that, in your opinion, did not "work well" in this particular lesson? If yes, what was that and why do you think that this was so? What improvement changes would you suggest (either long-term or short-term)?

4. Was there anything you found difficult/challenging in this particular lesson (e.g. the heterogeneity of learners etc.)? If yes, how did you try to resolve this? After watching the video, is there something you would do differently today?

5. Watching yourself in the video, do you notice any elements which you had not noticed before or which surprise you as far as your own presence in the classroom is concerned? (e.g. body stance, speed of speech, presence of teacher's voice in the classroom, pauses, range and type of feedback, activation of your learners' participation in the lesson etc.)? 


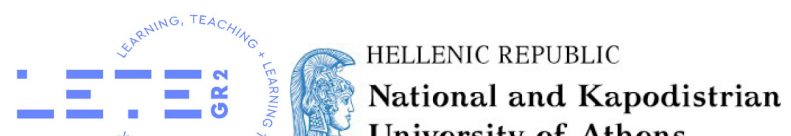 \\ University of Athens \\ EST. 1837}

6. While watching the video, do you notice any aspects you had not noticed before or some that surprise you as far as classroom management and the flow of the lesson is concerned? (learner participation, range and variety of participation, response to activities, aspects that indicate "loose" participation)?

7. After watching the video of your lesson, did any thoughts, concerns or ideas emerge about your future teaching practice? If yes, please mention some of these.

8. Do you believe that an occasional video-recording of your lessons, which would next provide a basis for self-reflection, could serve as an effective practice in your development as teachers?

9. Other comments related to the lesson (maximum length 150 words) (optional). 


\section{Appendix D}

Pre-service teacher's participant observation report (post-observation)

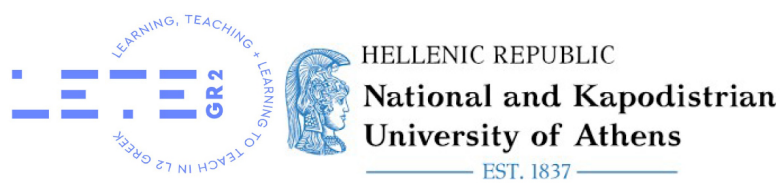

STUDENT'S NAME:

DATE:

\section{Participant Observation Report for pre-service teachers}

INSTITUTION: Modern Greek Language Teaching Center, University of Athens, Greece

INSTRUCTOR:

PROFICIENCY LEVEL:

UNIT:

SESSIONS:

NUMBER OF STUDENTS IN CLASS:

1. What did your observation focus on? What questions did you have before you observed the lesson? What were the issues that concerned you in relation to the lesson of Greek as an L2?

2. What did the lesson you observed consist of (in terms of content, topic, etc.)?

3. What did you learn from this particular observation? What surprised you pleasantly?

4. Is there anything that, in your opinion, did not "work well" in this particular lesson? If yes, what was that and why do you think that this was so? What improvement changes would you suggest (either long-term or short-term)?

5. Was there something you found difficult/challenging in this particular lesson (e.g. the heterogeneity of learners etc.)? If yes, how did the instructor try to resolve the particular issue?

6. Other comments related to the particular lesson (maximum length 250 words). 